\title{
3 Research Square \\ Cerebroplacental Ratio in The Prediction of Adverse Perinatlal Outcome in Postdte pregnancy - A prospective study
}

\section{Labake Victoria Ale}

Dept. of OB/GYN, University of Abuja

Nathaniel David Adewole ( $\square$ nadewole2013@gmail.com )

University of Abuja https://orcid.org/0000-0002-5803-2174

\section{Bilal Suleiman}

Dept. of OB/GYN University of Abuja Teaching Hospital

\section{Hadijat Oluseyi Kolade-Yunusa}

University of Abuja Teaching Hospital

Research article

Keywords: Postdate pregnancy, cerebroplacental ratio, perinatal outcome

Posted Date: October 7th, 2020

DOI: https://doi.org/10.21203/rs.3.rs-86192/v1

License: (9) This work is licensed under a Creative Commons Attribution 4.0 International License. Read Full License 


\section{Abstract}

BACKGROUND: Postdate pregnancies are associated with increased risk of fetal and maternal morbidity and mortality. The cerebroplacental ratio (CPR) is emerging as an important non-invasive tool to assess fetal wellbeing and predict adverse outcome in high risk pregnancies. The aim of this report was to evaluate the value of Doppler CPR in predicting adverse pregnancy outcome in the setting.

METHOD: This was a prospective study of 97 pregnant women from 40 weeks of gestation. Fetal Doppler evaluation of the pulsatility index (PI) of the umbilical artery (UA) and middle cerebral artery (MCA) were done and the CPR calculated as MCA-PI/UA-PI. The women were followed up until delivery the following data collected: the Apgar score, birth weight and information about SCBU admission.

RESULT: The women were aged $19-41$ years (mean 30.22 \pm 4.8 years) and the pregnancies were at $40-$ $41^{+3}$ weeks. The mean UA-PI, MCA-PI and CPR were $0.83 \pm 0.16,1.15 \pm 0.19$ and $1.42 \pm 0.31$, respectively. Abnormal UA-PI, MCA-PI and CPR were associated with an increased risk of adverse perinatal outcome (relative risk of 4.72, 7.08 and 9.78 respectively). Abnormal UA-PI was associated with fetal distress, abnormal MCA-PI was associated with fetal distress, low Apgar score at 1 minute and special care baby unit admission, and abnormal CPR was associated with fetal distress and low Apgar score at 1minute.

CONCLUSION: CPR is a good predictor of adverse perinatal outcome in postdate pregnancy and is recommended as an adjunct in evaluation of fetal wellbeing in this setting and similar settings.

\section{Background}

A postdate pregnancy is one that has exceeded the expected date of delivery (EDD) of 40 weeks or 280 days from the first day of last menstrual period (LMP). ${ }^{1,2}$ These are high risk pregnancies with substantial fetal and maternal risks. The incidence of postdate pregnancy in Nigeria have been reported at $3 \%-13 \%$ of total deliveries. ${ }^{2,5,6}$ These pregnancies require appropriate surveillance for early diagnosis as well as prediction morbidity and mortality.

Doppler ultrasound, a non-invasive method of fetal surveillance allows for assessment of the blood flow velocity waveform of maternal and fetal blood vessels including the uterine artery (UA), middle cerebral artery (MCA) and umbilical artery (UA). ${ }^{16,18}$ The fetal-placental circulation can also be assesseds. ${ }^{19,20,21}$ The fetal cerebroplacental ratio (CPR) is the ratio of the fetal MCA pulsatility index (PI) to UA PI. CPR has been noted to be a better predictor of adverse perinatal outcomes compared to other conventional anthropometric models. ${ }^{22}$

In Nigeria, the role of Doppler CPR to predict perinatal outcomes has not been adequately evaluated. The aim of this study was to assess the value of CPR in predicting adverse fetal outcome in postdate pregnancies. The working hypothesis was that CPR predicts adverse perinatal outcome in postdate pregnancies. 


\section{Methods}

The study was conducted at the Department of Obstetrics and Gynaecology, University of Abuja Teaching Hospital, Abuja, Nigeria, a 350-bed tertiary health facility. In this facility, modified biophysical profile is used to monitor postdate pregnancy. The major limitation is cardiotocography is not done due to unavailability of a functioning machine. With the availability of a modern ultrasound machine with a Doppler facility, a Doppler scan may be worthwhile in management of the postdate pregnancies.

This was a prospective observational study of women with uncomplicated postdate pregnancies at gestational age of $40-41^{+3}$ weeks, from August 2018-Febuary 2019. Women with singletons live fetus in cephalic presentation and accurate dating were included in the study. Women with the following were excluded; obstetric or medical complication(s) - IUGR, diabetes mellitus, hypertensive diseases in pregnancy, sickles cell disease, poor dating, multiple pregnancy, and breech presentation. A calculated sample size of 100 using: A calculated sample size of 100 (using $n=z^{2} p q / d^{2}$, where $n$ is sample size, $z$ is standard normal deviation (a constant) where $\mathrm{n}$ is sample size, $\mathrm{z}$ is standard normal deviation (a constant) which is 1.96 at $95 \%$ confidence interval at $95 \%$ confidence interval, $p$ is percentage of study population with abnormal CPR from a previous study, $q$ is $1-p$ and $d$ is margin of error of $5 \%$, and attrition of $10 \%$ ) was used. An informed consent was obtained from each woman before inclusion in the study.

At the time of the study, there was no facility for fetal blood sampling and measurement of blood gases to confirm fetal distress. Use of cardiotocography (CTG) was not possible due to a faulty CTG machine.

\section{Study Protocol}

Consent to participate were written and also verbally reaffirmed by the participants. After obtaining consent from the participants, the ultrasound was carried out using the General Electric Healthcare Voluson $^{\mathrm{TM}}$ P8 (2016 model) with Doppler unit and convex linear transducer 3.5 MHz. A basic scan was first conducted in B - Mode using the $3.5 \mathrm{MHz}$ curvilinear transducer to determine the viability, number, lie and presentation of the fetus as well as the placentation and liquor volume. A fetal biometry was carried out.

Using the same transducer and mode, a free loop of umbilical cord was located. The umbilical artery was identified using colour Doppler interrogation. Pulsed Doppler with a gate size of $2 \mathrm{~mm}$ was applied at an angle of insolation $\leq 30^{\circ}$. The pulsatility index $(\mathrm{PI})$ was automatically generated by the machine and value recorded when uniform consecutive waveforms were generated in the absence of fetal movement and breathing.

Pulsatility Index $(\mathrm{PI})=$ Peak systolic flow - end diastolic flow me an flow

Middle cerebral artery (MCA) Axial section of the brain, including the thalami and septum cavum pellucidi was obtained and magnified on B-Mode. Traducer was moved to the base of the skull until the circle of 
Willis was identified. The MCA was identified with colour Doppler. The scanning plane was adjusted to obtain an insonation angle close to $0^{\circ}$ but $<15^{\circ}$ at the level of the proximal portion of the MCA close to its origin from the circle of Willis with a sample volume of 2-3 $\mathrm{mm}$. Care was taken not to exert pressure on the fetal head because this alters the flow velocity waveforms from the MCA. The automatically generated pulsatility index $(\mathrm{PI})$ was recorded when uniform consecutive waveforms were generated in the absence of fetal movement and breathing. The right and left MCA pulsatility index was measured, and the mean recorded. The pulsatility index $(\mathrm{PI})$ and the cerebroplacental ratio was calculated using the formula:

Pulsatility Index (PI): Peak systolic flow - end diastolic flow me an f low

Cerebroplacental ratio $(\mathrm{CPR})=$ Middle Cerebral Artery-PI/Umbilical Artery $-\mathrm{PI}$

The Doppler evaluation was done once by the researcher and the consultant radiologist. Patients were followed up till delivery and relevant data collected. Cutoff values for normal and abnormal UA PI, MCAPI and CPR were generated using the 10th and 90 th percentile. The study population was divided into two groups based on normal and abnormal Doppler parameters.

Adverse perinatal outcome was defined as the presence of one or more of the following: Fetal distress, Apgar score $<7$ at 1 and 5 min, meconium aspiration syndrome (MAS) and admission into Special care baby unit (SCBU).

\section{DATA ANALYSIS}

Data was entered into a personal computer and analysis was done using the IBM Statistical Package for the Social Sciences (SPSS) version 23 software. A percentile plot of the Doppler variables was carried out and the UA PI was considered abnormal when the values were $>90$ th percentile while the MCA PI and CPR were considered abnormal when the values were $<10$ th percentile. Chi square was used for categorical variables and where the criterion for $X^{2}$ - test was not met, Fisher's Exact Test was used.

Primary outcome measures were fetal distress and birth asphyxia. Secondary outcome measures were: MAS, admission into SCBU, CS for fetal distress, PPH. MAS were diagnosed as visual observation of greenish discoloration of the liquor with respiratory difficulties. Fetal distress was defined as ominous FHR changes (tachycardia or bradycardia) that led to caesarean section or instrumental delivery.

\section{ETHICAL APPROVAL}

Approval for the conduct of the study was obtained from the Health Research and Ethics Committee of University of Abuja Teaching Hospital.

\section{Results}

\section{Demographics}


Of the 100 women recruited into the study, 3 were lost to follow and have been excluded from analysis. The demographics are summarized in table 1.

Table 1

Socio-demographic characteristics of 97 women included in the study

\begin{tabular}{|ll|}
\hline Variable & No. (\%) \\
\hline Maternal age (years) & $30.22 \pm 4.8$ \\
\hline Maternal height $(\mathrm{m})$ & $1.65 \pm 0.1$ \\
\hline Maternal weight $(\mathrm{kg})$ & $80.27 \pm 13.3$ \\
\hline Parity & $22(22.7)$ \\
\hline 0 & $74(76.3)$ \\
\hline $1-4$ & $1(1.0)$ \\
\hline$>4$ & $80(82.4)$ \\
\hline Gestational age & $17(17.5)$ \\
\hline $40-40^{+6}$ weeks & \\
\hline $41-41^{+3}$ weeks & $1(1.0)$ \\
\hline Educational status & $1(1.0)$ \\
\hline No formal education & $19(19.6)$ \\
\hline Primary & $76(78.4)$ \\
\hline Secondary & $78(80.4)$ \\
\hline Tertiary & $19(19.6)$ \\
\hline Mode of delivery & \\
\hline Spontaneous vagina & \\
\hline Caesarean section & \\
\hline Maternal age, height and weight are expressed as mean \pm SD, \\
\hline Parity, gestational age and mode of delivery are expressed as $\mathrm{n}(\%)$ \\
\hline
\end{tabular}

The commonest indication for caesarean section was foetal distress (42.1\%). Twenty-two women (22.68\%) had induction of labour, of which $18(81.8 \%)$ had a normal foetal outcome while $4(18.2 \%)$ had an adverse outcome $(p=0.23)$. Ten $(10.3 \%)$ of all the babies delivered had an adverse perinatal outcome 
while $87(89.7 \%)$ had a normal outcome. The composite adverse foetal outcome include: eight cases of foetal distress and four cases of four cases of one minute Apgar score less than 1.

Two $(2.06 \%)$ of the women had postpartum haemorrhage and $3(3.09 \%)$ had second degree perineal tears which were repaired. There was no maternal mortality.

\section{Umbilical artery pulsativity index}

The mean UA PI was $0.83 \pm 0.16$ (range $0.47-1.18$ ). Twelve fetuses had an abnormal UA PI and 85 had a normal UA PI. Four (33.3\%) foetuses with abnormal UA PI developed foetal distress resulting in caesarean section compared to $4(4.7 \%)$ with normal UAPI ( $p 0.001$, relative risk $>7$ ). There was no significant difference in the Apgar scores at 1 and 5-minute, admission into SCBU or meconium aspiration syndrome between foetuses with abnormal and normal UAPI. Foetuses with abnormal UAPI had a significantly higher total adverse perinatal outcome ( $p 0.005$, relative risk $>4$ ) (Table 2). 
Table 2

Relationship between UA PI, MCA PI, and perinatal outcome in 97 postdate pregnancies

\begin{tabular}{|c|c|c|c|c|}
\hline \multirow[t]{2}{*}{ Characteristic } & $\begin{array}{l}\text { Normal } \\
\text { Pulsatility Index } \\
(n=85)\end{array}$ & $\begin{array}{l}\text { Abnormal } \\
\text { Pulsatility Index } \\
(n=12)\end{array}$ & Value & $\begin{array}{l}\text { Relative Risk } \\
(95 \% \mathrm{Cl})\end{array}$ \\
\hline & No. (\%) & No. (\%) & & \\
\hline $\begin{array}{l}\text { UA PI (normal < 1.03; } \\
\text { abnormal } \geq 1.03 \text { ) }\end{array}$ & $4(4.7)$ & $4(33.3)$ & 0.001 & $\begin{array}{l}7.08(2.01- \\
14.98)\end{array}$ \\
\hline \multicolumn{5}{|l|}{ Fetal distress } \\
\hline APGAR score $<7$ at 1 minute & $13(15.3)$ & $3(25.0)$ & 0.40 & $\begin{array}{l}1.63(0.48- \\
3.81)\end{array}$ \\
\hline APGAR score $<7$ at 5 minutes & $1(1.2)$ & $1(8.3)$ & 0.10 & $\begin{array}{l}7.08(0.45- \\
51.79)\end{array}$ \\
\hline SCBU admission & $3(3.5)$ & $1(9.1)$ & 0.39 & $\begin{array}{l}2.58(0.27- \\
14.55)\end{array}$ \\
\hline Meconium aspiration & $1(1.19)$ & 0 & 0.72 & \\
\hline \multicolumn{5}{|l|}{ Perinatal outcome } \\
\hline Adverse outcome & $6(7.1)$ & $4(33.3)$ & 0.005 & $\begin{array}{l}4.72(1.47- \\
9.67)\end{array}$ \\
\hline Normal outcome & $79(92.9)$ & $8(66.7)$ & & \\
\hline \multicolumn{5}{|l|}{$\begin{array}{l}\text { MCA PI (normal < 0.90; } \\
\text { abnormal } \geq 0.90)\end{array}$} \\
\hline Fetal distress & $4(4.7)$ & $4(33.3)$ & 0.001 & $\begin{array}{l}7.08(2.01- \\
14.98)\end{array}$ \\
\hline APGAR score $<7$ at 1 minute & $10(11.8)$ & $6(50.0)$ & 0.001 & $\begin{array}{l}4.25(1.81- \\
6.69)\end{array}$ \\
\hline APGAR score $<7$ at 5 minutes & $1(1.2)$ & $1(8.3)$ & 0.10 & $\begin{array}{l}7.08(0.45- \\
51.79)\end{array}$ \\
\hline SCBU admission & $2(2.4)$ & $2(16.7)$ & $0.02^{*}$ & $\begin{array}{l}7.00(1.04- \\
25.72)\end{array}$ \\
\hline Meconium aspiration & 0 & $1(8.3)$ & 0.008 & \\
\hline Perinatal outcome & $5(5.9)$ & $5(41.7)$ & \multirow[t]{3}{*}{$\begin{array}{l}<.001 \\
0.01\end{array}$} & \multirow{3}{*}{$\begin{array}{l}7.08(2.42- \\
12.83)\end{array}$} \\
\hline Adverse outcome & $80(94.1)$ & $7(8.3)$ & & \\
\hline Normal outcome & & & & \\
\hline
\end{tabular}

UA PI: Umbilical artery pulsatility index: MCA PI: Middle cerebral artery pulsatility index; CPR:

Cerebroplacental ratio: $\mathrm{Cl}$ : Confidence interval; SCBU: Special care baby unit 


\begin{tabular}{|c|c|c|c|c|}
\hline \multirow[t]{2}{*}{ Characteristic } & $\begin{array}{l}\text { Normal } \\
\text { Pulsatility Index } \\
(n=85)\end{array}$ & $\begin{array}{l}\text { Abnormal } \\
\text { Pulsatility Index } \\
(n=12)\end{array}$ & $\mathrm{p}$ Value & $\begin{array}{l}\text { Relative Risk } \\
(95 \% \mathrm{Cl})\end{array}$ \\
\hline & No. (\%) & No. (\%) & & \\
\hline \multirow{2}{*}{$\begin{array}{l}\text { CPR (normal < 1.02; abnormal } \\
\geq 1.02 \text { ) }\end{array}$} & $\mathrm{n}=\mathbf{8 8}$ & $n=9$ & & \\
\hline & No. (\%) & No. (\%) & & \\
\hline Fetal distress & $4(6.8)$ & $4(22.2)$ & $<.001$ & $\begin{array}{l}9.78(2.92- \\
17.75)\end{array}$ \\
\hline APGAR score $<7$ at 1 minute & $12(13.6)$ & $4(44.4)$ & 0.02 & $\begin{array}{l}3.26(1.16- \\
5.67)\end{array}$ \\
\hline APGAR score $<7$ at 5 minutes & $1(1.14)$ & $1(11.1)$ & 0.05 & $\begin{array}{l}9.78(0.62- \\
60.44)\end{array}$ \\
\hline SCBU admission & $3(3.4)$ & $1(12.5)$ & 0.22 & $\begin{array}{l}3.67(0.38- \\
17.88)\end{array}$ \\
\hline Meconium aspiration & 0 & $1(12.5)$ & 0.001 & \\
\hline \multicolumn{5}{|l|}{ Perinatal outcome } \\
\hline Adverse outcome & $5(5.7)$ & $5(55.6)$ & 0.001 & $\begin{array}{l}9.78(3.56- \\
15.14)\end{array}$ \\
\hline Normal outcome & $83(94.3)$ & $4(44.4)$ & & \\
\hline
\end{tabular}

\section{Middle cerebral artery pultativity index}

The mean MCA PI was $1.15 \pm 0.19$ (range 0.66 - 1.18). Twelve foetuses had an abnormal MCA PI and 85 had a normal MCA PI. These were the same foetuses that had abnormal UA PI. Foetuses with abnormal MCA PI had significantly increased risk of developing foetal distress resulting in caesarean section, Apgar score $<7$ at the $1^{\text {st }}$ minute and admission into SCBU (p 0.001, 0.001 and 0.02 respectively, relative risk $>7$, 7 and $>4$ respectively). There was no significant difference in the Apgar scores at 5 minutes between foetuses with abnormal and normal MCA PI (Table 3). There was a statistically significant difference between the two groups in the total adverse perinatal outcome $(P<0.001)$ with a relative risk $>7$. (Table 2$)$.

\section{Cerebroplacental ratio (CPR)}

The mean CPR was $1.42 \pm 0.31(0.8$ - 2.4). Nine (9.3\%) foetuses had an abnormal CPR and 88(90.7\%) normal CPR. Foetuses with abnormal CPR were found to be at a significantly increased risk of developing foetal distress resulting in caesarean section and an Apgar score $<7$ at the $1^{\text {st }}$ minute $(p<0.001$ and 0.002 
respectively, and relative risk $>9$ and $>3$ respectively). There was no significant difference in the Apgar scores at 5-minute, admission into SCBU or meconium aspiration syndrome between foetuses with abnormal and normal CPR. There was significantly more total adverse perinatal outcome in foetuses with abnormal CPR $(p<0.001$, relative risk $>9)$. (Table 2, Figure 1$)$. There were no stillbirths or early neonatal deaths in any group.

The sensitivity, specificity, positive predictive value and negative predictive value was estimated for the UA PI, MCA PI and CPR. The area under the curve $\{A U C\}$ for CPR and MCA PI were statistically significant with a $P$ value of 0.02 and 0.03 respectively when compare to normal.

\section{Discussion}

Although there is insufficient evidence to recommend a management strategy for pregnancies beyond 40 weeks, management options include, expectant management with antepartum testing, induction of labour and caesarean section when indicated. ${ }^{8,9}$ Initiation of fetal surveillance at 41 weeks is considered a reasonable option and improvements in antepartum fetal surveillance methods has led to a reduction in perinatal morbidity and mortality $.5,{ }^{8}$ The options of fetal surveillance include, fetal kick charts ,Biophysical profile (BPP), Modified BPP, Amniotic fluid volume (AFV), Non stress test (NST), contraction stress test, Doppler studies and a combination of these modalities. ${ }^{9,10,11}$

In the present report, fetal distress was the most common indication for caesarean section the 19 (19.6\%) participants who had procedure. The mean UA PI, MCA PI and CPR were $0.83,1.15$ and 1.42 , respectively. These values fell within the reference ranges in another report at gestational ages of between $41-41^{+3}$ weeks. ${ }^{12}$ Important information was obtained with regards to the relationship between indices for adverse perinatal outcomes and, UA-PI, MCA-PI, and CPR.

The cut-off value for an abnormal UA PI generated in the present study was $\geq 1.03$. Fetuses with an abnormal UA PI were shown to be at a significantly increased risk of fetal distress resulting in caesarean section similar to other reports. ${ }^{13-16}$ An abnormal UA PI also resulted in more than a four-fold increase in the risk of an adverse perinatal outcome. This may support the theory that adverse perinatal outcome in postdate pregnancy is due to placental insufficiency with an increased impedance in the umbilical artery leading to increased resistance and reduced blood flow. ${ }^{14}$ However, severe degrees of umbilical Doppler abnormalities such as absent or reversed end diastolic flow are rare findings in postdate pregnancy and are associated with poor outcomes. ${ }^{13}$ Other reports found no change in impedance to blood flow in the UA and UA Doppler was not a useful predictor of adverse perinatal outcome. ${ }^{17.18}$

Fetuses with an abnormal MCA-PI cut off of $\leq 0.9$ were at an increased risk of fetal distress resulting in caesarean section, APGAR score $<7$ at the $1^{\text {ST }}$ minute, admission into SCBU and a more than seven-fold increased risk of adverse perinatal outcome as in other reports. ${ }^{13,16,19,20}$ This may support the theory of a brain sparing (BS) phenomenon in postdate pregnancies with an adverse outcome. However, other reports have found women with an adverse outcome to have normal MCA-PI. ${ }^{18.21,22}$ This has been 
explained that in uncomplicated postdate pregnancies, the mechanism of fetal compromise is perhaps due to a decrease in flow of nutrients across the placenta and decrease in efficiency of utilization of nutrients by the placenta and the fetus and not uteroplacental insufficiency with a resultant BS effect. ${ }^{18}$ In the present report, MCA-PI had a better predictive value for adverse perinatal outcome in postdate pregnancies compared to UA PI as in other reports. ${ }^{16,19}$

Using a cut-off value of $\leq 1.02$ for abnormal CPR, $9.3 \%$ of the study fetuses had an abnormal CPR. An abnormal CPR had a positive correlation with fetal distress resulting in caesarean section, APGAR score < 7 at the $1^{\mathrm{ST}}$ minute and more than nine-fold increased risk of an adverse perinatal outcome, as in other reports. ${ }^{5,7,13,16,23}$ Although the UA-PI and MCA-PI alone did not predict adverse outcome in another report, CPR with a cut off at 1.3 had a high sensitivity and negative predictive value. ${ }^{18}$ This supports the use of the CPR even in the presence of an apparently normal UA-PI and MCA-PI to predict adverse perinatal outcome.

Among the three Doppler parameters studied, the CPR had the best discriminatory ability to predict foetuses likely to have an adverse perinatal outcome with a specificity of $95.4 \%$ and sensitivity of $50 \%$. MCA-PI closely follows, with the same sensitivity as the CPR (50\%) and slightly lesser specificity (92\%). MCA-PI was however the only parameter with a significant positive correlation with admission into the SCBU. This is similar to other reports. ${ }^{13,16,23,24}$ Although the sensitivity, specificity, positive predictive and negative predictive values for CPR in the present report were lower than previously reported, 5,13,16,23 the difference may be due to the addition of high risk women with postdate pregnancies as in another report, ${ }^{12}$ or due differences in cut-off values used and the frequency of Doppler measurements.

\section{Conclusion}

CPR can predict adverse perinatal outcome irrespective of the individual UA-PI and MCA-PI. The high specificity and negative predictive value of CPR provides a good indication of fetal wellbeing and could help in preventing unnecessary interventions. Doppler CPR should be used to complement other antepartum parameters in the surveillance of postdate pregnancy. A systematic review and meta-analysis is needed to further ascertain the role of CPR in routine surveillance of postdate pregnancy.

\section{Abbreviations}

CPR Cerebroplacental ratio

PI Pulsatility index

UA Umbilical artery

MCA Middle cerebral artery

SCBU Special Care Baby Unit 
EDD Expected date of delivery

LMP Last menstrual period.

SPSS Statistical Package for the Social Sciences.

MAS Meconium aspiration syndrome

CS Caesarean section

PPH Postpartum Haemorhage

\section{Declarations}

Ethical approval and consent to participate: Ethical approval was obtained from University of Abuja Teaching Hospital ethical committee. The approval reference number was UATH/HREC/PR/2018/06/001.

Informed consent for the patients were written and verbally reaffirmed;

Consent for publication: Not applicable

Availability of data and materials: Data used are not publicly available due to difficult in sending to database. But the data are available from the corresponding author on request

Competing interest: The authors declare that they have no competing interests

Funding: The research was funded by the authors

\section{Authors' contributions:}

OVA was involved in conception, design of the work, data acquisition and interpretation of data NDA was involved in the designing of the work, interpretation of data and writing of the article BS was involved in the concept, designing and interpretation of data.

HOY was involved in designing, collection of data and analysis of the data

All authors have gone though and approved the final write up.

Acknowledgement: We wish to acknowledge the contribution of Prof EA Ameh in editing the article

\section{References}


1. Punya BS, Mpa S. Study of post-dated and term pregnancy with foetomaternal outcome at RRMCH. Int J Obstet Gynaecol Res. 2017;4(2):179-183

2. Azubuike IJ, Bassey G, Okpani AOU. Comparison of 25 and 50 microgram of misoprostol for induction of labour in nulliparous women with postdate pregnancy in Port Harcourt. Niger J Clin Pract. 2015;18(2): 263-267

3. Patel N, Modi P. A Study of Maternal and Fetal Outcome in Postdate Pregnancy. IJSR.2017; 6(9): 2015-8.

4. Cunningham FG, Levono KJ, Bloom SL, Hauth JC, Rouse DJ, Spong CY, editors. Post term pregnancy. Williams Obstetrics. Twenty fourth edition, McGraw- Hill, New York, 2014: Pp862- 871.

5. Wang KG, Chen CY, Chen CYY. The effects of absent or reversed end-diastolic umbilical artery Doppler flow velocity. Taiwanese J Obstet Gynaecol. 2009; 48(3):225-31.

6. Mieko R, Yamamoto N, Niigaki Jl, Horigome FT, Pulcineli R, Francisco V et al. Doppler velocimetry of the fetal middle cerebral artery and other parameters of fetal well-being in neonatal survival during pregnancies with placental insufficiency. Rev Assoc Med Bras. 2013; 59(4):392-399.

7. Bligh LM, Alsolai AA, Gree RM, Kumar S, Cerebro-placental ratio thresholds measured within two weeks of birth and the risk of cesarean for intrapartum fetal compromise and adverse neonatal outcome. Ultrasound Obstet Gynaecol 2018; 52(3):340-346.

8. Dobariya PV, Shah PT, Ganatra HK. Foeto-maternal outcome in pregnancy beyond 40 weeks. Int J Reprod Contracept Obstet Gynaecol. 2017; 6(2):527-531.

9. American College of Obstetricians and Gynaecologists. Practice bulletin No 146: Management of late-term and post term pregnancies. Obstet Gynaecol. 2014; 124(2 Pt 1):390-6.

10. Bako BG, Obed JY, Sanusi I. Methods of induction of labour at the University of Maiduguri Teaching Hospital, Maiduguri: A 4-year review. Niger J Med. 2008; 17:139-42.

11. Ropacka-Lesiak M, Korbelak T, Świder-Musielak J, Breborowicz G. Cerebroplacental ratio in prediction of adverse perinatal outcome and fetal heart rate disturbances in uncomplicated pregnancy at 40 weeks and beyond. Arch Med Sci. 2015;11(1):142-148.

12. Roman AS. Late pregnancy complications. In: Decherney AH, Nathan L, Laufer N, Roman AS editors. Current Diagnosis \& Treatment, Obstetrics and Gynecology. Eleventh edition. McGraw Hill Companies, New York, 2013; Pp250-266.

13. Yalti S, Oral O, Gürbüz B, Özden S, Atar F. Ratio of middle cerebral to umbilical artery blood velocity in preeclamptic \& hypertensive women in the prediction of poor perinatal outcome. Indian J Med Res 2004: 44-50.

14. DeVore GR. The importance of the cerebroplacental ratio in the evaluation of fetal wellbeing in SGA and AGA fetuses. Am J Obstet Gynaecol.2015; 213(1):5-15.

15. Ozel A, Alici Davutoglu E, Yildirim S, Madazli R. Fetal cerebral and cardiac hemodynamics in postdate pregnancy. J Matern Fetal Neonatal Med. 2018; 26:1-6. 
16. Maghed AM, Abdelhafez A, Al Mostafa W, Elsherbiny W. Fetal middle cerebral and umbilical artery Doppler after 40 weeks gestational age. J Matern Fetal Neonatal Med. 2014; 27(18):1880-5.

17. Malcus P, Marsal K, Persson P-H. Fetal and uteroplacental blood flow in prolonged pregnancies. A clinical study. 1991; 1: 40-45.

18. Usha G, Chandra S, Narula MK. Value of middle cerebral artery to umbilical artery ratio by Doppler velocimetry in pregnancies beyond term. J Obstet Gynecol India. 2006; 56(1):37-40.

19. Anteby EY, Tadmor O, Revel A, Yagel S. Post-term pregnancies with normal cardiotocographs and amniotic fluid columns: the role of Doppler evaluation in predicting perinatal outcome. Eur J Obstet Gynaecol Reprod Biol. 1994; 54:93-8.

20. Lam H, Leung WC, Lee CP, Lao TT. The use of fetal Doppler cerebroplacental blood flow \& amniotic fluid volume measurement in the surveillance of postdated pregnancies. Acta Obstet Gynaecol Scand 2005; 84:844-8.

21. Brar HS, Horenstein J, Medearis AL, Platt LD, Phelan JP, Paul RH. Cerebral, Umbilical, and Uterine Resistance Using Doppler Velocimetry in Post term Pregnancy. J Ultrasound Med.1989; 8:187- 191.

22. Chandran R, Serra-Serra V, Sellers SM, Redman CW. Fetal cerebral Doppler in the recognition of fetal compromise. Br J Obstet Gynaecol 1993; 100(2):139-44.

23. El-Sokkary M, Omran M, Ahmed H. Ratio of Middle Cerebral Artery / Umbilical Artery Doppler Velocimetry and Status of Newborn in Post term Pregnancy. J Am Sci. 2011; 7(4): 542-549.

24. Prior T, Paramasivam G, Bennett $P$, Kumar $S$. Are fetuses that fail to achieve their growth potential at increased risk of intrapartum compromise? Ultrasound Obstet Gynaecology 2015; 46: 460-464.

\section{Table 3}

Table 3 is not available with this version

\section{Figures}




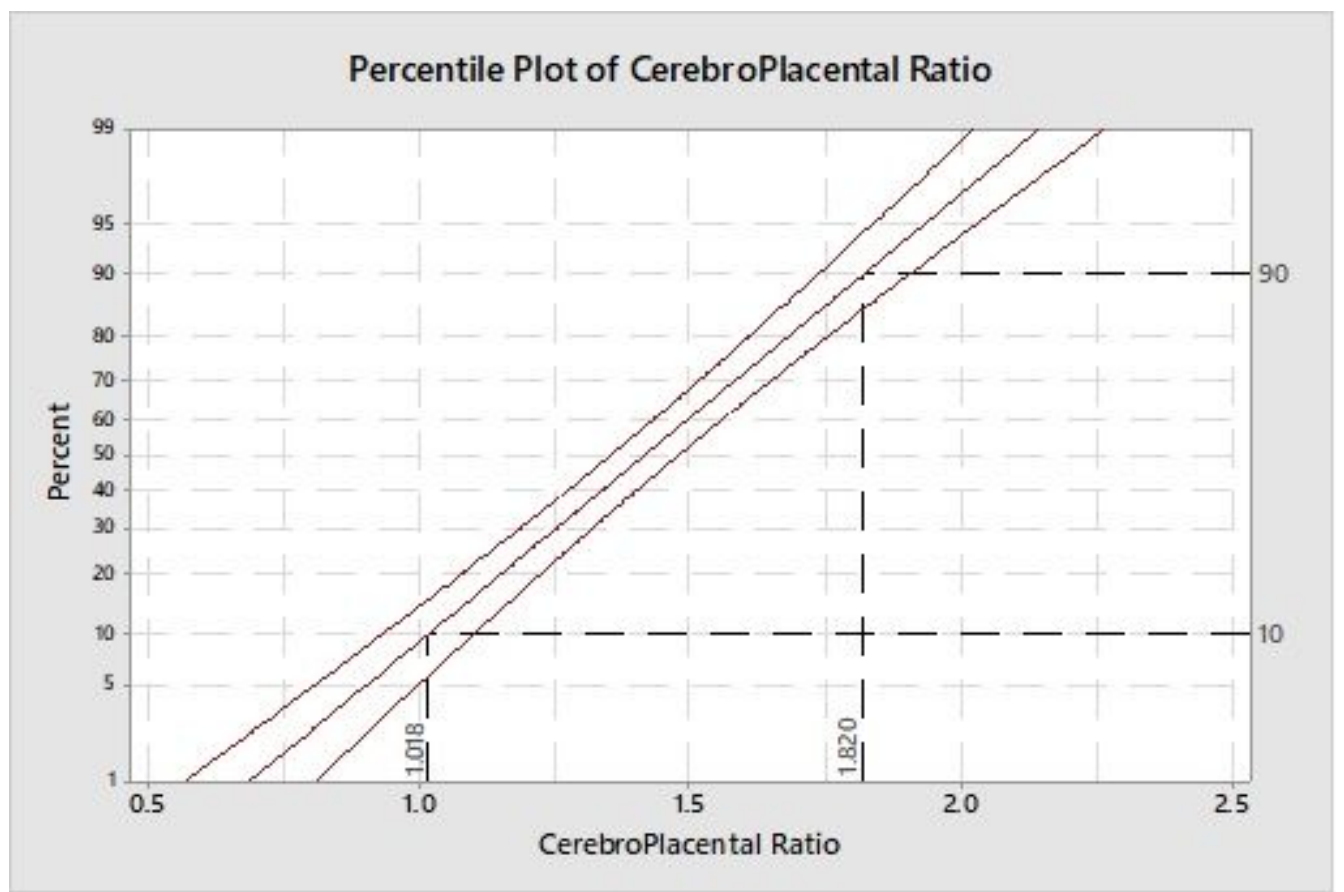

Figure 1

Percentile Plot of CerebroPlacental Ratio 